\title{
THE EFFECTIVENESS OF VIDEO AND PAMPHLETS IN INFLUENCING YOUTH ON ENVIRONMENTAL EDUCATION
}

\author{
Jamilah Ahmad, Gowri Sritharan \\ $\&$ Nur Nasliza Arina Mohamad Nasir \\ Universiti SAINS MaLAysia
}

\begin{abstract}
Environmental problems are getting worse nowadays. The importance of Environmental Education, particularly to the youth is crucial because youth are the leaders of the future and play significant roles in determining the direction of the country. This study aims to explore the effectiveness of video and pamphlets in influencing youth on Environmental Education. This study also determines to find the best medium to educate youth on Environmental Education be it video or pamphlet. The Social Cognitive Theory by Albert Bandura was used as a theoretical framework and a qualitative method of focus group was carried out in order to collect data from respondents. Findings indicated that respondents had a higher preference for the video as an Environmental Education medium as opposed to pamphlets.
\end{abstract}

Keywords: Environmental education, mass media, video, pamphlets, youth 


\title{
KEBERKESANAN VIDEO DAN RISALAH DALAM MEMPENGARUHI BELIA MENGENAI ALAM SEKITAR
}

\begin{abstract}
Abstrak
Masalah melibatkan alam sekitar semakin meruncing pada masa kini. Oleh itu, Pendidikan Alam Sekitar adalah sangat penting terutamanya kepada belia kerana mereka merupakan pemimpin masa hadapan di samping memainkan peranan yang signifikan dalam menentukan hala tuju negara. Kajian ini adalah bertujuan untuk mengetahui keberkesanan video dan risalah dalam mempengaruhi belia terhadap Pendidikan Alam Sekitar. Kajian ini juga berminat untuk mengenalpasti di antara video dan risalah, yang manakah boleh digunakan sebagai medium terbaik dalam mendidik belia terhadap Pendidikan Alam Sekitar. Kajian ini menggunakan Teori Kognitif Sosial oleh Albert Bandura sebagai kerangka teori di samping mengaplikasikan penyelidikan kualitatif melalui kumpulan fokus dalam mengumpulkan data daripada responden. Hasil kajian mendapati, video menjadi pilihan utama responden sebagai medium terbaik dalam mempengaruhi belia terhadap Pendidikan Alam Sekitar berbanding dengan risalah.
\end{abstract}

Kata kunci: Pendidikan alam sekitar, media massa, video, risalah, belia

\section{INTRODUCTION}

Environmental issues are continually gaining attention worldwide because of the impact it leaves on the lives of people and the well being of the planet. Our modern environmental problems are crucially interwoven with our personal relationship to nature. The connectedness between individuals and the natural environment therefore can counter the current environmental problems (Lieflander et al., 2013). Not only are governments and various organisations directing policies and efforts towards environmental conservation, but they are recognising the crucial need for Environmental Education.

According to Palmer and Neal (1994), Environmental Education is the sole and obvious answer to address the ecological catastrophes taking place today. In their opinion, Environmental Education will not only make people aware of the harm they continually do to the environment in the name of progress, but also inform them on how they can merge progress and life in a way that both can 
exist together. Moreover, Environmental Education can also engage people of all ages to make informed decisions about these and similar issues, and to undertake actions appropriate to their local context (NAAEE, 1996; UNESCO, 1978).

This study focuses on the role of the media in Environmental Education. According to Mohd Yusof (2010), the mass media is not only a tool or instrument used to convey important information, but it can also build perception and the attitude of the public towards the information that is presented. The media has, over the years, acquired a reputation for being able to influence the thoughts and actions of viewers, thus serving as a tool in promoting ideas. As Pope (1996) writes, media coverage is the single biggest factor shaping the political debate on the future of the planet.

The impact of the media on the public has changed over the years as the medium itself has evolved, and is continually evolving today. Whiteman (2004) observes that early studies in 1954 by Berelson, Lazarfeld and McPhee found that the mass media had minimal effects on voting and public opinion. Subsequent research by Entman in 1993 and McCombs and Shaw in 1973 found that the mass media has since begun to demonstrate greater impact, particularly in agendasetting and framing effects. This could be due to the rise and proliferation of the broadcast media, reaching a wider range of audience and influencing them by means of audio and visuals. Mohanty (2008) adds that since the emergence of various media, millions of people have come to acquire new ideas, philosophies, approaches and attitudes.

This study contends that the inefficient dissemination of environmental knowledge among the public is the main cause for their lack of awareness. This is due to the selection of an inappropriate form of media to disseminate information and to educate society, thus falling short in providing the necessary knowledge. Specifically, the media takes on three main forms, the print, broadcast and new media, each with its own pros and cons. To effectively deliver environmental knowledge, the most suitable media or teaching tools has to be identified and applied. This finding could shed light on how to tailor environmental education to better influence people and change their behaviour towards positive environmental practices.

The two mediums selected in this study were video and pamphlet, each respectively representing the broadcast and print media. The environmental video and pamphlet used in this study acts as a social influence within the environment, which conveys information and activates emotional reactions through modelling, instruction and social persuasion. This influences the student's personal factors such as expectations, beliefs, perceptions, goals, and intentions. These personal factors give shape and direction to behaviour (Bandura 1986). For example, respondents may be influenced by the video and pamphlet enough to change their behaviour towards conserving the environment. In this case, the extent of change can be directly related to the effectiveness of the medium, with the more effective medium resulting in greater positive change. 


\section{LITERATURE REVIEW}

\section{Environmental Education}

Environmental Education started from the Stockholm Conference held in 1972 and it was usually claimed to be at the centre of efforts to achieve sustainable development (Habibah and Punitha, 2012; Blum 2008). According to Heimlich and Ardoin (2008), Environmental Education is a process for intellectual growth using environment as the context. Effective Environmental Education and its interpretation clearly depend on the understanding that the audiences' values, attitudes and beliefs, particularly towards a specific issue or a site-specific resource. The previous Environmental Education research has concentrated on knowledge or attitudinal outcomes, and few studies have examined the ability of Environmental Education programmes to promote relatedness with nature (Lieflander, et.al, 2013).

Athman and Monroe (2001) stated that, effective Environmental Education programs are relevant to the mission of the agency or organisation, to the educational objectives of the audience, and to the everyday lives of the individual learners. An agency or organisation's mission and environmental priorities provide direction for program development in Environmental Education, guiding the development of goals and objects and their choice of target audience. On the other hand, Environmental Education is not the presentation of information but it helps learners achieve environmental literacy, which has attitude and behaviour component in addition to a knowledge component. The goal of Environmental Education is to instill learners on the knowledge of the environment, positive attitudes towards the environment, competency in citizen action skills, and a sense of empowerment (Disinger and Monroe, 1994).

Besides that, Environmental Education is also about experiencing, sharing, creativity, pleasure and sensitivity. Environmental Education activities can be about informing the population, discovery activities such as guided visits, games, and outings. It can also consist of the active participation of the public like workshops, volunteering, excursions, role play, field trips or holidays (Wagner et al., 2011). Thus, Environmental Education leads to an increase in social awareness and sensitivity, the production of knowledge necessary for the protection of the environment, and the inquiry into methods necessary for tackling environmental problems (Dresner and Blawner, 2006).

In Malaysia, the importance of Environmental Education is highlighted in the National Policy on the Environment 2002, and one of the key areas of the Green Strategies outlined in the policy is 'Education and Awareness'. The promotion of Environmental Education in Malaysia is focused towards addressing environmental challenges such as littering, water pollution, air pollution and the degradation of biodiversity. Various federal and state government departments, the private sector, educational institutions and non-governmental organisations (NGOs) are actively promoting Environmental Education in both formal and non-formal arenas. The target groups are from all levels of society such as 
teachers, students, government agencies, developers, restaurant operators, industries/factory owners and the general public (Pudin, 2006).

According to Singh and Serina (2012), the role in public Environmental Education and awareness by non-governmental organisations (NGO's) in Malaysia is becoming increasingly important as social mobility and affluent lifestyles are more prevalent among their citizens. Environmental Education and conservation groups have long been lobbying those in power and financiers of projects to implement sustainable environmental policies, be responsible for environmental management and at the same time, educate the general public. Without the educational component, NGO's will not be successful in lobbying for change in public policy and winning public perception. As a conclusion, there is no doubt that Environmental Education is critically important as an effort to enlighten the public on the importance of preserving and conserving the environment for the sake of all parties. In addition, Environmental Education is also important in educating the public to appreciate and love the environment as part of their daily lives.

\section{Videos as an Educational Tool}

The success of documentaries and videos are measured by evaluating its effectiveness in informing, clarifying and imparting ideas to the audience. Numerous studies, from as early as 1946 to as recent as 2009, conclude that videos and documentaries are an excellent mode of education. Hoban (1947) wrote that documentaries play a vital role in the learning process, where its function is to dramatize some significant social situation and to develop an awareness of the condition, thus a willingness on the part of the viewer to do something about it. A year later, Pratzner (1947) wrote that all motion pictures have two main functions, one as a medium of entertainment and the other as an educational tool. He found that educational leaders agreed that documentary films are important. In school classrooms, business offices, factories, and community halls for example, it quickens perception and shortens learning time, while promoting the retention of a particular idea.

Rabiger (1987) verified that in a pluralistic society committed to the principles of free speech, documentaries play a vital role in forming public opinion. He adds that documentary makers have a strong respect for the integrity of the actual and for the truth in the lives of real people, both great and small. The documentary maker's mission is not to change or question destiny, but rather to accept it, and to present critical issues with passion and urgency. This would establish the right opinions among viewers, which will then lead towards a humane and generous society.

Studies conducted in more recent years better portrays the effectiveness of documentaries as a teaching tool as opposed to earlier studies. This is because recent studies take into account elements of technological advancements and change in human behaviour and culture. Thus, such studies represent the broadcast media and its influence on society the way it is today. Another recent 
study by Shdaimah (2009) looked at the role of documentary films in teaching social policy. She concluded that documentaries should be used as a pedagogical tool to better understand social policy, because this medium is especially suited to provide perspectives that often go unheard of in policy debates, academic discussions and textbooks.

In contrast to the studies and opinions previously mentioned, several scholars disagree that the visual broadcast is a promising educational tool. They conclude that videos and documentaries may hinder the learning process rather than reinforce it, and thus the conventional textbook method still remains to be the most effective mode of education. Chu and Schramm (1967), for example, found that visual images were able to improve the learning process only in cases where students could associate and relate to the visuals presented. When the association process failed, the use of visual images only interfered with their learning. Chu and Schramm (1967) add that the amount of learning is proportional to the student's degree of attention. This, they say, is significantly lower in mass media situations than in the usual classroom situations where theories of learning have been developed.

To summarize, there are still arguments on the effectiveness of videos as an educational tool to disseminate knowledge to the public. However, according to the U.S. Environmental Protection Agency (2010), there are several benefits of video as an educational tool such as it can discuss an issue in depth, allows control over the content, can be visually appealing, can be aired on cable TV stations and can be accessed online through the internet. . Besides that, there are split reviews and perceptions towards the use of videos in the field of education. Early studies by scholars like Hoban (1947), Pratzner (1947), Klapper (1960), Rabiger (1987) as well as more recent studies by Thomas (1999), Samuel (2008), Shdaimah (2009) and Glenn (2010) agree that documentaries do play a vital role in shaping public opinions and providing knowledge. On the other hand, Chu and Schramm (1967) remain convinced that, documentaries are not suitable as an educational tool. They further express their concern that the use of documentaries as an educational tool may hinder the traditional classroom method of learning.

\section{Pamphlets as an Educational Tool}

Pamphlets are print materials which usually contain educational information, a tutorial of some sort or certain instructions which could be beneficial to the reader. According to Newell (1996), pamphlets are relatively easy and cheap to produce and can also be distributed widely. In the health promotion field, pamphlets have become a very popular and widely used form of intervention. This can be seen when the NSW Cancer Council alone had distributed over 103 million written education materials during the 1992-1993 financial year. However, pamphlets are likely to have little effect in many situations.

Besides that, as reported by U.S. Environmental Protection Agency (2006), pamphlets can be easily exhibited and distributed to a big population and they 
can be made using simple materials and graphics, or can be made more elaborate. Pamphlets are self-explanatory and they can be distributed at libraries, schools, offices and fairs. They can also be handed out at meetings or sent in direct mail campaigns. However, it is important to think about the purpose of creating a pamphlet because this will help define the appearance and content of the material.

According to Gawwad and El-Herishi (2007), pamphlets are great educational tools for disseminating knowledge on a particular issue. The study conducted by them adds proof to the effectiveness of pamphlets as an educational tool for increasing staff knowledge about asthma. This is based on the results of the study; the respondents' mean initial total knowledge score (maximum possible 39) was 28.16 , increased significantly to 34.32 after the intervention process. This proved that there was a large significant increase in the respondents' subtotal knowledge scores about nature of asthma, symptoms, triggers, management and medication.

Luz, Schaal and Rabello (2005) conducted a study to evaluate the use of pamphlets as a tool for providing information on the disease Visceral Leishmaniasis to healthcare professionals and laypersons. The sample for their research consisted of 551 healthcare workers and 379 laypeople from southeast Brazil, whereas the methodology employed was survey questionnaire. Participants completed a multiple-choice questionnaire both before and after reading the pamphlet. It was found that there was an increased proportion of correct answers after reading the pamphlet, evidence of the pamphlet's potential as an educational tool.

However, not all studies were able to conclude that pamphlets are effective educational tools. Another Australian health-related study was carried out by Turnbull and Irwig (1992) to determine the influence of leaflets in urging members of the public to attend mammogram screening services. In this study, leaflets were dropped in every house over 79 selected streets, whereas another 78 control streets were chosen for the purpose of comparison. The findings revealed that attendance to the screening service did not vary much between the two.

The main problem contributing to the ineffectiveness of pamphlets as an educational tool is the level of language difficulty used. Pamphlets are designed for large groups within society, consisting of individuals who have varying education levels and reading abilities. As such, pamphlets which may suit individuals with high reading levels may not be understandable to individuals with low reading levels. Similarly, individuals with high reading levels may not accept and pay importance to low reading level materials (Davis et al., 1996).

In conclusion, it is clear that pamphlets have been widely used as a means of educating the public on critical issues, particularly health-related topics. Pamphlets prove to be cost-effective, convenient and easy to circulate, which make it a medium of choice for disseminating knowledge to the larger public. As stated by the U.S. Environmental Protection Agency (2010), there are several benefits of pamphlets as an educational tool such as can reach a large audience, can be more technical than other formats, can tailor messages for 
specific audiences for different publications, go beyond building awareness by providing detailed information, reach more educated audiences, audience can clip, reread, and think about the material, might provide more credibility, often low-cost (with unit prices decreasing with quantity) and good to use as a followup mechanism. However, studies such as that of Turnbull and Irwig (1992) have showed that pamphlets do not leave an impact on the receiver, and thus, do not serve as an effective educational tool. This is justified by underlying reasons such as diversity in the target group, especially with regards to educational level and reading level.

\section{METHODOLOGY}

This research applied a qualitative method of focus group in order to collect the data from the respondents. 100 respondents consist of youth age between 20-28years old were selected at random to participate in this study. Focus group discussion involved ten participants for each group. The 14 minute environmental video and pamphlet used in this study was "Let's Go Green", a production for the Environmental Research Video by Universiti Sains Malaysia (USM) produced by Dr Jamilah Ahmad. Verbatim translation of the video was converted into a 16 page pamphlet, which discusses four main environmental issues, namely pollution, energy, waste management and natural disasters.

Each issue was discussed in terms of the factors causing the problem and the ways in which to overcome them. The content, facts, photographs, colour theme, design and layout was similar (verbatim) as in the video to ensure consistency and minimizing possibility for any of these to act as variables. A group discussion was carried out to analyse how respondents view environmental message, also if the received knowledge could lead to behavioural change and which of the two mediums are most appropriate for environmental education, and if so why. In this manner, ten focus group sessions were carried out over the course of this study.

The theoretical framework supporting this study is Albert Bandura's Social Cognitive Theory, which suggests that human behaviour is the result of interaction between three components, which are personal factors, behaviour and the environment (Bandura 1986). According to Social Cognitive Theory, watching others performing behaviour influences the observer's perceptions of their own ability to perform the behaviour, and this influences the expected outcomes (Compeau 1995). This theory contends that behaviour is regulated through cognitive processes, suggesting that the mind is an active force that constructs one's reality, selectively encodes information, performs behaviour, and imposes structure on its own actions. This theory also emphasizes that reinforcement influences the cognitive process which leads to learning (Jones 1989). 


\section{RESULTS AND DISCUSSION}

The result is based on five main questions that were asked to the respondents during the focus group discussion. The questions were: (1) general perceptions towards the environmental video and pamphlet; (2) perceptions towards content of environmental video and pamphlet; (3) perceptions towards design and layout of environmental video and pamphlet; (4) effectiveness of video and pamphlet in creating environmental awareness; and (5) suggestions on using the video and pamphlet as an educational tool.

\section{General Perceptions towards the Environmental Video and Pamphlet}

From the responses obtained, it was found that the majority of participants enjoyed watching the video as opposed to viewing the pamphlet. This was further evident when four male participants from Focus Group 4 had stated that the pamphlet was not at all enjoyable. This was an expected outcome as the video contained elements which are more enjoyable than the pamphlet, for example a voice-over or narration, background music, and a large amount of visuals which could not be incorporated into the pamphlet. However, some respondents had expressed their interest to view the pamphlet for the second time and not the video. In their opinion, the duration of the video is long (approximately 14 minutes) and too heavy in terms of content. As such, viewers lose interest in the topic as the video approaches the end. The pamphlet on the other hand, allows respondents to read at their own time and flip back to previous pages if necessary.

The majority of respondents said they would recommend the video to friends, and the same majority stated that the video should be made available to the general public. As such, it is safe to say that the respondents' overall perception towards the video is positive and more welcoming as opposed to the pamphlet. Although the majority of the respondents verbally expressed keen interest in watching the video and reading the pamphlet, the information presented was not new to them. However, it reinforced their pre-existing knowledge about the environment.

This might indicate that youth in Malaysia does have fairly basic information on how important to preserve environment and why. However, what is lacking is the practice and the initiative to change or overcome their 'do not care' attitude. A particular respondent with sciences background (female, 25 years old, Focus Group 7) said that although the information was not new, the video contained background music which stirred her emotion and attracted her to the subject matter. In addition, the use of a voice-over or narration meant that she could focus on the visuals being presented and was not required to read.

\section{Perceptions towards Content of Environmental Video and Pamphlet}

Respondents were also asked questions regarding the content of the video and pamphlet. Specifically, participants were asked if the content was interesting and easy to understand, if the information presented was new, useful and able to capture their attention, and if the message conveyed was clear. All 100 
participants stated that both the video and pamphlet had content which was understandable, interesting and useful. They also added that the message was clear, although the information presented may not be new to them.

A majority of the respondents said that they first gained environmental knowledge while in primary school. Activities such as gardening, recycling and planting trees, which were carried out as part of the school curriculum, have instilled the importance of the environment in them. They added that secondary education further taught them about the environment. School subjects like science and biology disseminated environmental knowledge from a scientific approach. By the end of secondary education, participants agreed that they could identify the main environmental issues and talk about relevant solutions. However, again the majority of respondents admitted that they did not begin practicing such solution until much later.

When it came to the content of the two mediums, (some/majority of the) respondents admitted that the video captured their attention more than the pamphlet did. This was based solely on the fact that the video contained various elements which were absent in the pamphlet. These include the background music which plays an important role in getting the audience emotionally connected to the video, a clear and understandable narration to take the viewers through the video from start to end, and a larger collection of visuals which demonstrate in detail the issues discussed in the video.

\section{Perceptions towards Design and Layout of the Environmental Video and Pamphlet}

Besides content, another aspect of the video and pamphlet which the respondents were required to talk about was the design and layout. They were asked if the design was interesting and eye-catching, if the font was clear, if the arrangement of visuals and texts was appropriate, if the pictures presented were relevant, whether it is new to them and whether it captured their attention, and if they prefer to have more pictures and/or texts. In general, all 100 participants felt the overall design of both medium were interesting.

However, (some/majority of the) respondents preferred the colour concept, font, and the arrangement of visual and texts in the pamphlet more than in the video. Although both medium were produced in a way to standardize as much of the layout as possible, some elements could not be perfected. The colour concept is difficult to maintain in the video as with the pamphlet, because the program used to create the video, Adobe Premier Pro 2.0, does not facilitate that. In addition, it is a common practice to produce videos with more visuals than font, adding to the inconsistency between the layout of the pamphlet and video.

According to (some/majority of) the respondents, the colour concept of the pamphlet was vibrant and it stressed on the environmental theme. In their opinion, the use of various shades of green and blue highlighted the borders and created depth to the background of each page. This was effective in capturing the interest of viewers. These colours, however, were not present in the video, where 
the main colour concept was black.

With regards to the choice of visuals, a majority of the respondents agreed that the shots and pictures used in both the video and pamphlet were relevant to the topic. The shots on the video matched the narration, while the pictures on the pamphlet complemented the texts it was intended for. By referring to the pictures as they read, the respondents said they could better relate to the topic. However, they added that the visuals were not new to them. 95 percent of the respondents said they have come across similar pictures or seen similar scenes in real life before. As such, they would have liked to see a bigger collection of unique and unusual visuals, something out of the ordinary which would capture the viewer's attention.

\section{Effectiveness of Video and Pamphlet in Creating Environmental Awareness}

A part of this study was directed at determining if the participants' awareness towards environmental issues had heightened after watching the environmental video and reading the pamphlet. They were asked if they knew what the worst environmental issues were and if they could name the factors causing it. They were also asked if they knew what environmental destruction looked like, how everyday human activity contributes to it, and how to avoid harming the environment.

In addition, respondents were asked if they knew how their actions in the past may have caused harm to the environment, how to advice others about being caring towards the environment, and where to go for more information about such issues. After watching the video and viewing the pamphlet, the majority of participants agreed that they were aware of the worst environmental issues, what is causing the problem, how everyday human activities can contribute to environmental destruction and what that destruction looks like. 99 participants out of 100 said they were environmentally aware even prior to watching the video or reading the pamphlet. Only one of the male respondents (Focus Group 8) said he was not aware that environmental destruction was so serious.

The majority of respondents were also aware about ways in which to avoid harming the environment, and feel they are knowledgeable enough to advice other members of the public on environmental conservation. 32 out of 100 respondents said that they have been involved in environmental campaigns and programs which have put them in a position to advice the public on environmentally-friendly practices. 9 out of those respondents (Focus Groups 1, 3, 6 and 7) are currently involved with the works of Malaysian Nature Society (MNS) and World Wildlife Fund Malaysia (WWF-Malaysia).

When asked what efforts they have carried out to benefit the environment, recycling was the most common answer. The remaining responses included using less motorized vehicles, using public transport or walking when possible, saving paper by avoiding unnecessary printing, reducing the use of plastic bags, completely avoiding the use of Styrofoam, using reusable food containers 
instead, saving electricity where possible, and harvesting rain water.

A majority of respondents had admitted that they now realize how their actions in the past may have harmed the environment. While most respondents expressed guilt and regret, a group of three friends in Focus Group 10 said those action were unavoidable and necessary in the name of profit. However, a majority of respondents said they now feel motivated to change their actions in order to save the environment in future.

\section{Suggestions on Using the Video and Pamphlet as an Educational Tool}

Participants were asked to give suggestions on how to improve on the environmental video and pamphlet in order to use it as an educational tool. Where both mediums were concerned, majority of the respondents expressed that adding statistics is important in both medium so that people know the gravity of the situation through researched facts, figures and data. In addition, a hotline or contact number of a complaint body for environmental issues, which includes website details, could be helpful and useful.

The majority of the respondents suggested that the overall duration of the video be reduced to approximately 10 minutes. In their opinion, a long video becomes boring after the first half, and viewers start losing interest. This decreases their attention during the later part of the video, which contains crucial information on natural disasters, especially landslides. The respondents also found the narration long and wordy. They would have preferred less narration and more sequences with just visuals and background music. This, they said, would allow the viewers to better process and remember the information being disseminated.

With regards to the pamphlet, the majority of the respondents suggested that the information be simplified and written in point form instead of whole paragraphs. They would have preferred fewer texts and more pictures with captions. They would have also enjoyed reading sentimental quotes about the environment, which in their opinion would have added to the emotional aspect of the pamphlet. Respondents also suggested the inclusion of references on the last page of the pamphlet. This would make it easier for the viewers to refer to sources for additional information or clarification on an issue.

\section{CONCLUSION}

This study aims to determine the most effective medium to convey an environmental message to youth in Malaysia. It can be concluded that the majority of the respondents agreed that video can have a better impact and play a better role to educate environmental education in Malaysia. Application in video was more interesting and captured the attention of viewers, while the background music and off-screen narration further added to the effectiveness of the video in influencing viewers. Since the emerging of new media, youth engage themselves more with technology; therefore in the real world scenario distributing pamphlets to educate the public may not be feasible. In addition, printing large amount of 
pamphlets for any purposes is not environmentally friendly, contradicting the purpose of the effort which is to heighten environmental awareness.

A similar study was carried out by Schnellinger et al. (2010) to determine which of the two mediums, video or pamphlet, was a more effective educational medium in the field of medicine. The objective was to create an animated video to teach parents about the appropriate use of antibiotics and to compare their knowledge to parents who were provided with a pamphlet of similar content. Schnellinger et al. (2010) concluded that the animated video was exceedingly more effective than the pamphlet and it also resulted in long-term knowledge retention. The findings of this research study can be applied to general environmental education, by suggesting that school, colleges and education institutes alter their mode of disseminating environmental knowledge. The use of videos as a teaching tool may provide better understanding and promote higher consciousness towards the environment.

The conclusion of this study can answer to The Social Cognitive Theory, by Bandura, which defines human behaviour as an interaction between the person, environment and behaviour. Here, the respondents act as the person, the environmental video acts as a social influence within their environment, and their reactions towards the video act as behaviours. This social influence (video) has conveyed information and activated emotional reactions (person) through modelling, instruction, and persuasion, as depicted in the video. The emotional reactions within them will then influence their beliefs, perceptions, goals and intentions, which in turn give shape and direction to ones behaviour. Although the pamphlet contained instructions, it lacked modelling and persuasion because of print constraints as opposed to visuals on the video. This explains the respondents' preference towards the video and why a majority of them were better influenced by it as opposed to the pamphlet.

In short, participants were able to watch a behaviour being performed in the video, which could influence their cognition, or in other words their thinking and perception, towards the environment. It is hoped that their changed cognition will continue to affect their behaviour towards better environmental practices. The pamphlet on the other hand was less influential because it does not demonstrate behaviour in the way the video does. As such, the influence it had on the cognition of viewers was minimal. This finding could shed light on how to tailor environmental education to better influence people and change their behaviour towards positive environmental practices.

\section{ABOUT THE AUTHORS}

Jamilah Ahmad is an Associate Professor at School of Communication, Universiti Sains Malaysia and is currently researching on Environmental Communication, Public Relations, Corporate Social Responsibility (CSR), Communication \& Media Studies, e-Learning and New Media Technology. Email: jahmad@usm. my. 
Gowri Sritharan is a Master of Communication student (Science and Environmental Journalism) at School of Communication, Universiti Sains Malaysia.

Nur Nasliza Arina Mohamad Nasir is a PhD student (Communication) at School of Communication, Universiti Sains Malaysia.

\section{REFERENCES}

Athman, J.A., and Monroe, M.C. (2001). Elements of Effective Environmental Education Programs. Retrieved at http://www.d.umn.edu/ kgilbert/ educ5165-731/Readings/Elements\%20of\%20Effective\%20EE.pdf

Bandura, A. (1986). Social Foundations of Thought and Action: A Social Cognitive Theory. Englewood Cliffs NJ: Prentice-Hall.

Blum, N. (2008). Environmental Education in Costa Rica: Building a framework for sustainable development? International Journal of Educational Development, 28(3), 348-358.

Chu, G.C., and Schramm, W. (1967). Learning from Television: What the Research Says. Stanford CA: Stanford University Press.

Compeau, D.R., and Higgins, C.A. (1995). Application of social cognitive theory to training for computer skills. Information Systems Research, 6(2), $118-143$.

Davis, T., Arnold, C., Berkel, H., Nandy, I., Jackson, R., and Glass, J. (1996). Knowledge and attitude on screening mammography among low-literate low-income women. Cancer, 78(9), 1912-1920.

Disinger, J.F., and Monroe, M.C. (1994). Defining Environmental Education. EE Toolbox-Workshop Resource Manual. National Consortium for Environmental Education and Training: Ann Arbor MI.

Dresner, M., and Blawner, J.S. (2006). Approaching civic responsibility using guided controversies about Environmental Issues. College Teaching, 54(2), 213-220.

Gawwad, E.S.A., and El-Herishi, S. (2007). Asthma education for school staff in Riyadh City: Effectiveness of pamphlets as an educational tool. Journal Egypt Public Health Association, 82 (1- 2): 147-171.

Habibah, L., and Punitha, M. (2010). Environmental Education (EE): Current situational and the challenges among trainee teachers at teachers training institute in Malaysia. Procedia Social and Behavioural Sciences, 2(2), 1896-1900.

Heimlich, J.E., and Ardoin, N.M. (2008). Understanding behaviour to understand behaviour change: A literature review. Environmental Education Research, 14(3), 215-237.

Hoban, R. (1947). Education for social work. In First Australian Conference for Social Work, Sydney, Australia, 87-94.

Jones, J.W. (1989). Personality and epistemology: Cognitive social learning 
theory as a philosophy of science. Zygon, 24(1), 23-38.

Lieflander, A.K., Frohlich, G., Bogner, F.X., and Schultz, P.W. (2013).

Promoting connectedness with nature through Environmental Education.

Environmental Education Research, 19(3), 370-384.

Luz, Z.M., Schaal, V., and Rabello, A. (2005). Evaluation of a pamphlet on

Visceral Leishmaniasis as a tool for providing disease information to healthcare professionals and laypersons. Cad Saude Publica, 21(2), 606621.

Mohanty, P. (2008). Mass Media \& Education. New Delhi: APH Publishing Corporation.

Mohd Yusof, H.O. (2010). Media dan isu alam sekitar. Jurnal Hadhari, 2(2), $1-17$.

NAAEE. (1996). Environmental education materials: guidelines for excellence. Washington

DC: North American Association for Environmental Education.

Newell, S. (1996). Writing Effective Pamphlets: A Basic Guide. Newcastle: Southern Cross University.

Palmer, J., and Neal, P. (1994). The Handbook of Environmental Education. London: Routledge.

Pope, C. (1996). Retrieved at http://findarticles.com/p/articles/mi_m1525/ is_n2_v81/ai_18041083/

Pratzner, W.F. (1947). What Has Happened to the Documentary Film? Public Opinion Quarterly, 11(3), 394-401.

Pudin, S. (2006). Overview of Environmental Education and Awareness Programmes in Sabah.

In Fourth Sabah-Sarawak Environmental Convention 2006, 1-14.

Rabiger, M. 1987. Directing the Documentary. Boston MA: Focal.

Schnellinger, M., Finkelstein, M., Thygeson, M.V., Velden, H.V., Karpas, A., and Madhok, M.

(2010). Animated video Vs pamphlet: Comparing the success of educating parents about proper antibiotic use. Pediatrics, 125(5), 990-996.

Singh, H.R., and Serina, A.R. (2012). An approach for Environmental Education by non-governmental organisations (NGO's) in Biodiversity Conservation. Procedia - Social and Behavioral Sciences, 42, 144-152.

Shdaimah, C. (2009). The power of perspective: Teaching social policy with documentary film. Journal of Teaching in Social Work, 29(1), 85-100.

Turnbull, D., and Irwig, L. (1992). Ineffective recruitment strategies for screening mammography: Letterbox drops and invitations for friends. Australia Journal Public Health, 16(1), 79-81.

UNESCO. (1978). The Tbilisi Declaration. Report, USSR, Tbilisi, October.

United States Environmental Protection Agency. (2006). Retrieved at http://cfpub.epa.gov/npdes/stormwater/menuofbmps/index.cfm?action=bro wse \&Rbutton $=$ detail\& $b m p=11$ 
Wagner, M., Fagot, M., Verre, J., Doler, A., and Vogrin, M. (2011).

Environmental Education: Contribution to a sustainable future. European Regional Development Fund, 1-32.

Whiteman, D. (2004). Out of theatres and into the streets: A coalition model of the political impact of documentary film and video. Political Communication, 21(1), 51-69. 